\title{
Genetic Determinants of Ethanol-Induced Liver Damage
}

\author{
Adriana Monzoni, ${ }^{1,2}$ Flora Masutti, ${ }^{2}$ Gioconda Saccoccio, ${ }^{2}$ Stefano Bellentani, ${ }^{2}$ Claudio Tiribelli, ${ }^{2}$ \\ and Mauro Giacca ${ }^{1,3}$ \\ ${ }^{1}$ Molecular Medicine Laboratory, International Centre for Genetic Engineering and Biotechnology (ICGEB), \\ Padriciano 99, 34012 Trieste, Italy \\ ${ }^{2}$ Fondo per lo Studio delle Malattie del Fegato, Via Donota 1, 34121 Trieste, Italy \\ ${ }^{3}$ Scuola Normale Superiore, Piazza dei Cavalieri 7, 56126 Pisa, Italy \\ Accepted [add date]
}

\begin{abstract}
Background: Although a clear correlation exists between cumulative alcohol intake and liver disease, only some of the alcohol abusers develop signs of ethanol-induced liver damage. To identify some of the genetic variations predisposing persons to alcoholic liver disease (ALD), a genetic study was performed in heavy drinkers from the cohort of the Dionysis study, a survey aimed at evaluating liver disease in the open population of two towns in Northern Italy (6917 individuals).

Materials and Methods: 158 heavy drinkers $(\sim 85 \%$ of all heavy drinkers in the population; daily alcohol intake $>120 \mathrm{~g}$ in males and $>60 \mathrm{~g}$ in females) were investigated by the analysis of nine polymorphic regions, mapping in exons III and IX of the alcohol-dehydrogenase (ADH)-2 gene, in exon VIII of the ADH3 gene, in intron VI, in the promoter region of the cytochrome P4502El (CYP2E1) gene, and in the promoter region of the tumor necrosis factor- $\alpha$ gene.

Results: Heavy drinkers with or without ALD significantly differed for the distribution of alleles of the cytochrome
\end{abstract}

P4502E1 (CYP2E1) and alcohol-dehydrogenase-3 (ADH-3) genes. In one town, allele $\mathrm{C} 2$ in the promoter region of the CYP2El gene had a frequency of 0.06 in healthy heavy drinkers, of 0.19 in heavy drinkers with ALD $(p=0.012)$, and of 0.33 in heavy drinkers with cirrhosis $(p=0.033)$. In the other town, whose inhabitants have different genetic derivation, a prominent association between ALD and homozygosity for allele ADH $3 * 2$ of ADH3 was found, with a prevalence of 0.31 in heavy drinkers with ALD and of 0.07 in healthy heavy drinkers controls $(p=0.004)$.

Conclusions. Both heterozygosity for allele C2 of CYP2E1 and homozygosity for allele $\mathrm{ADH} 3 * 2$ of $\mathrm{ADH} 3$ are independent risk factors for ALD in alcohol abusers. The relative contribution of these genotypes to ALD is dependent on their frequency in the population. Overall, heavy drinkers lacking either of these two genotypes are 3.2 and 4.3 times more protected from developing ALD and cirrhosis respectively.

\section{Introduction}

Alcoholic liver disease (ALD) results from a complex interaction between behavioral, environmental, and genetic factors. Although several studies have defined a close relationship between cumulative alcohol intake and risk of developing liver damage (1-4), extensive individual variability still exists in disease susceptibility. Even among heavy drinkers (>100 g alcohol per day), only some individuals develop clinical, biochemical, and histological signs of ALD, ranging from $6-41 \%$ in the different studies $(5,6)$.

The importance of genetic factors in the predisposition to ALD has long been recognized (7). Genes encoding for enzymes with alcohol dehydrogenase (ADH2, ADH3) and aldehyde dehydrogenase (ALDH2) activities, for components of the microsomal ethanol oxidation system (cytochrome P4502E1), or for proteins potentially mediating

Address correspondence and reprint requests to: Professor Mauro Giacca; Head, Molecular Medicine Laboratory; ICGEB; Padriciano, 9934012 Trieste, Italy. Phone: +39-040-375 7324. Fax: +39-040-226555. E-mail: giacca@icgeb.trieste.it liver damage (tumor necrosis factor- $\alpha$, TNF- $\alpha$ ) have been the main subjects of investigations in the last years (8-20). Overall, the results obtained by these studies have been quite contradictory. Some studies conducted in the Japanese and Chinese population indicated that allele $\mathrm{ADH} 2 * 2$ of the $\mathrm{ADH} 2$ gene (17), allele ALDH2*2 of the ALDH2 gene $(8,21)$, and allele $\mathrm{C} 2$ of the CYP2El gene (12) were associated with ALD, but other investigations failed to confirm these findings $(8-10,15,21)$. In Caucasians, some studies indicated that allele C2 of the CYP2E1 gene (16), allele $\mathrm{ADH}^{*}{ }^{*} 1$ of the $\mathrm{ADH} 3$ gene (18), and allele TNFA of the TNF- $\alpha$ gene (22) were more prevalent in patients with ALD. However, most of these findings have been subsequently either contradicted by other studies $(11,13,14)$ or methodologically questioned (23).

Altogether, the conflicting results so far obtained clearly reflect the overall problem of addressing the investigation of a multifaceted disease such as ALD. From the clinical standpoint, major problems in the study design have often been the small number of disease patients and controls available, with their derivation from a selected series and not from an 
open population, thereby making a precise disease definition difficult (both in terms of liver damage and levels of alcohol consumption). From the genetic standpoint, several of these studies had been conducted in genetically heterogeneous populations with an uncontrolled rate of genetic admixture, often by analyzing the contribution of alleles rare in the overall population (such is the case of the $\mathrm{C} 2$ allele in the Caucasian population). Additionally, ALD is definitely a complex trait, in which polymorphisms in several genes are likely to be involved, yet most of the studies so far conducted have analyzed the association of one or few alleles with the disease at a time, and not of more complex genotypic associations.

Given these considerations, we decided to take advantage of the availability of the heavy drinkers, both with and without ALD, obtained through the Dionysos Study, a cohort study that investigated the prevalence of chronic liver disease in a general population (24). This study involved the analysis of 6917 individuals from two towns in Northern Italy (Campogalliano and Cormons), representing approximately $70 \%$ of the total open population. Because the inhabitants of the two towns have different historical derivation, this sample provided an invaluable tool for the analyses of allelic frequencies in two homogenous, unselected populations.

\section{Materials and Methods Patients}

In the framework of the Dionysos Project $(6,24)$, all the 10,151 inhabitants aged 12-65 years of two Northern Italy communities were considered eligible for the study, of whom 6917 were carefully evaluated for the presence of liver disease $(70 \%$ compliance to participate in the study [6]). All individuals with cirrhosis, hepatocellular carcinoma, or initial alteration of aminotransferases (ALT and AST) or $\gamma$-glutamiltransferase (GGT) were also followed up every 6 months from 1993 to 1997. The amount of alcohol intake was studied through a semi-quantitative, color-illustrated food questionnaire $(25,26)$, including detailed questions on the use of alcoholic beverages (6). Out of 6917 individuals initially examined, 186 hepatitis B virus surface antigen and anti-hepatitis $C$ virus negative subjects resulted to drink $>120 \mathrm{~g}$ alcohol per day (for males; $n=147$ ) or $>60 \mathrm{~g}$ alcohol per day (for females; $n=39$ ) for at least 10 years. These heavy drinkers individuals were recalled and re-examined in 1997. Six men and 22 women declared themselves to have quit drinking alcohol at least 5 years earlier, and thus, were discharged from this study. 158 persons who remained heavy drinkers (141 men and 17 women) were finally enrolled in this genetic study. The estimated lifetime total amount of ethanol drunk by these subjects examined was 1702 \pm 1061 and $596 \pm 388 \mathrm{~kg}$ per person, respectively.
All the heavy drinkers with cirrhosis or with persistent levels of either ALT or AST or GGT 1.5fold as the upper normal range in at least six out of the eight 6-month interval checks and who showed signs of steatosis at ultrasonography were classified as having alcoholic liver disease (ALD). Patients were considered affected by cirrhosis when at least two of the following features were present: 1) spider nevi, scleral icterus, palmar erythema, ascites, flapping tremor, and hepatic or spleen enlargement; 2) platelet count less than 140,000 ; or 3 ) portal vein diameter greater than $12 \mathrm{~mm}$ at ultrasonography. The diagnosis of alcoholic cirrhosis, clinically established according to this criteria, was always confirmed by liver biopsy. The remaining patients with ALD and without clinical signs of cirrhosis either refused biopsy or biopsy was not justified on ethical grounds. According to these criteria, 66 patients were diagnosed as having ALD (61 men and 5 women), out of whom 15 had cirrhosis.

\section{DNA Isolation and PCR Amplification}

Total genomic DNA was obtained from $10 \mathrm{~mL}$ peripheral blood samples collected in EDTA or heparin according to standard procedures (27). PCR amplification reactions were conducted on 200-ng sample DNA in $50 \mu \mathrm{l}$ PCR buffer solution $(0.2 \mathrm{mM}$ each nucleotide, $1.5-2.0 \mathrm{mM} \mathrm{MgCl} 2,50 \mathrm{mM} \mathrm{KCl}, 10 \mathrm{mM}$ Tris-HCl pH 8.3, 20 pmol each primer, and $1 \mathrm{U}$ Taq polymerase [Amplitaq, Perkin Elmer, Emmeryville, CA]). Reactions were carried out using 35 thermal cycles with the following cycle profiles: hot start at $95^{\circ} \mathrm{C}$ for $5 \mathrm{~min}$, denaturation at $94^{\circ} \mathrm{C}$ for $30 \mathrm{sec}$, annealing at $56^{\circ} \mathrm{C}$ for the polymorphisms of the CYP2El gene (Rsa I, Pst I, Dra I, Msp I) and ADH3 gene (Ssp I), $57^{\circ} \mathrm{C}$ for the polymorphisms of the ADH2 gene (Alu I and Mae III) and $59^{\circ} \mathrm{C}$ for the -308 and -238 polymorphisms of the TNF- $\alpha$ gene (Nco I and Msp I) for $30 \mathrm{sec}$, extension at $72^{\circ} \mathrm{C}$ for $30 \mathrm{sec}$, and final elongation at $72^{\circ} \mathrm{C}$ for $7 \mathrm{~min}$. Oligonucleotide primers for polymorphisms Pst I and Rsa I (28), Dra I and Msp I (14) of CYP2E1, Mae III and Alu I of ADH2 (29), Ssp I of ADH3 (29), Nco I and Msp I of TNF- $\alpha$ (22) have already been described.

\section{Restriction Enzyme Analysis of the Polymorphic Loci}

Amplified DNA was digested with commercially available (Boehringer Mannheim, Mannheim, Germany and New England Bioloabs, Beverly, MA) restriction endonucleases at $37^{\circ} \mathrm{C}$ for $5 \mathrm{hr}$ (Rsa I, Pst I, Dra I, Msp I, Ssp I, Alu I, and Nco I) and at $55^{\circ} \mathrm{C}$ for $5 \mathrm{hr}$ (Mae III) under conditions recommended by the manufacturers. The amplified and digested DNA fragments were resolved by $2 \%$ agarose or $10 \%$ polyacrylamide gel electrophoresis as appropriate, stained by ethidium bromide and photographed.

\section{Statistical Analysis}

Allele and genotype frequencies were calculated using the $G$ test $(30)$, a likelihood ratio test that is 
equivalent to the $\chi^{2}$ test, but it less sensitive to very low expected values (31). For all significant values, a Fisher's exact test gave similar results. All the reported $p$ values are without correction for multiple tests. The threshold to assess statistical significance of the $p$ values was lowered according to the Bonferroni procedure for multiple tests (four tests, considering four as the number of unlinked markers analyzed in the whole data set (32)). Odd Ratios (O.R.) and $95 \%$ confidence intervals (C.I.) were also calculated (33).

\section{Results}

Alcohol Consumption and Demographic Features of the Population Studied

The overall design of the Dionysos Study has already been described (24). Briefly, all the 10,151 inhabitants 12-65 years old of two northern Italian communities were considered eligible for the study, of whom 6917 were carefully evaluated for the presence of liver disease. Out of those, 141 males and 17 women drinking $>120 \mathrm{~g}$ or $>60 \mathrm{~g}$ alcohol/day respectively for at least 10 years were enrolled in the genetic study presented here. These individuals represent $\sim 85 \%$ of the total heavy drinkers of the population. Out of these 158 heavy drinkers, 66 were defined as having ALD, of whom 15 with cirrhosis. A detailed description of the inclusion criteria and of the criteria for the definition of ALD is reported in the Methods section. The possible bias in selection toward oversampling from different members of the same families was ruled out by the intra-familial analysis revealing that the percentage of subjects belonging to the same families was less than $3 \%$. No statistically significant differences were found between heavy drinkers with ALD and healthy heavy drinkers controls, either for age $(57.9 \pm 7.6$ vs. $57.5 \pm 10.1$; mean \pm SD) or for daily initial and lifetime alcohol intake (134.7 \pm 63.6 vs. $137.3 \pm 65.3 \mathrm{~g}$ of alcohol per day; $1535 \pm$ 1111 vs. $1628 \pm 1038 \mathrm{~kg}$ of alcohol per lifetime). Other results from multivariate analyses of different parameters in these individuals have already been reported (6).

\section{Allelic and Genotypic Distributions in Heavy Drinkers}

The distributions of nine genetic polymorphisms in four different loci (ADH2, ADH3, CYP2E1, and TNF- $\alpha$ genes) were studied in the defined heavy drinker population. A schematic representation of the localization of the analyzed polymorphic sites is presented in Figure 1 and the functional significance of the different alleles that are generated are briefly summarized in the figure legend.

The allelic distribution of the four analyzed genes is shown in Table 1 for both the two separate towns and for the total number of individuals. With the exception of two subjects in Campogalliano, all heavy drinkers individuals were homozygous for allele $\mathrm{ADH} 2 * 1$ of the $\mathrm{ADH} 2$ gene. Similarly, allele MSPI2 in intron VI of the CYP2El gene was very rare $(0.013$ allele frequency) in both populations. Alleles G and A in the promoter of TNF- $\alpha$ gene (position -238) were equally distributed both in healthy heavy drinkers controls and in heavy drinkers with alcoholic liver disease. In contrast, allele 2 of polymorphism -308 at the TNF- $\alpha$ gene promoter was more present in healthy heavy drinkers ( 19 out of $88 ; 0.22$ allele frequency) than in heavy drinkers with liver disease (7 out of $70 ; 0.10$ ). However, the probability value of this distribution $(p=0.046)$ is below the threshold of statistical significance if the Bonferroni correction for multiple tests is applied (see Methods).

In heavy drinkers from Campogalliano, a striking difference was found for the distribution of the two alleles of the promoter region of cytochrome P4502E1. In this population, allele C2 was present only in 6 out of 96 alleles (0.06) from healthy heavy drinkers controls, but it was present in 12 out of $62(0.19 ; p=0.012)$ heavy drinkers with ALD and 4 out of 12 heavy drinkers with cirrhosis $(0.33 ; p=0.033)$. Thus heavy drinkers subjects with at least one $\mathrm{C} 2$ allele have a relative risk of 3.8 times higher (C.I. 1.2-11.9) of developing ALD, and of 9.2 times higher (C.I. 1.5-55.8) of developing alcoholic cirrhosis.

By the analysis of genotype frequencies in the population of heavy drinkers from Campogalliano, we found that the distribution of alleles $\mathrm{C} 1$ and $\mathrm{C} 2$ of CYP2El was in strong linkage disequilibrium with that of alleles D and C of the Dra I polymorphism in the intron VI of the same gene (Table 2). Although the two independent genotypic distributions follow the Hardy-Weinberg equilibrium, when the combined genotypes were considered, a clear co-segregation of allele C of the intronic Dra I polymorphism with allele $\mathrm{C} 2$ of the Rsa I promoter polymorphism could be observed $(p<0.001)$. This allelic association is in favor of the conservation of ancestral chromosomal segments in this population and is likely to indicate its genetic homogeneity. Neither allele $C$ of the Dra I polymorphism alone nor its genotypic combinations could be statistically associated to the development of ALD (data not shown).

The results reported above indicate that the presence of allele C2 of P4502E1 even in heterozygosity is a major determinant for alcoholic liver damage in heavy drinkers from Campogalliano. This conclusion can be drawn also when the genotypic distribution is analyzed (Table 3). In Campogalliano, only 6 out of $48(12 \%)$ normal heavy drinkers individuals have at least one allele $\mathrm{C} 2$, whereas this is present in 11 out of $31(36 \%)$ and 4 out of $6(67 \%)$ heavy drinkers with ALD and cirrhosis, respectively $(p=0.016$ for heavy drinkers with ALD vs heavy drinkers controls; $p=0.010$ for cirrhotic $v$ s noncirrhotic subjects). 


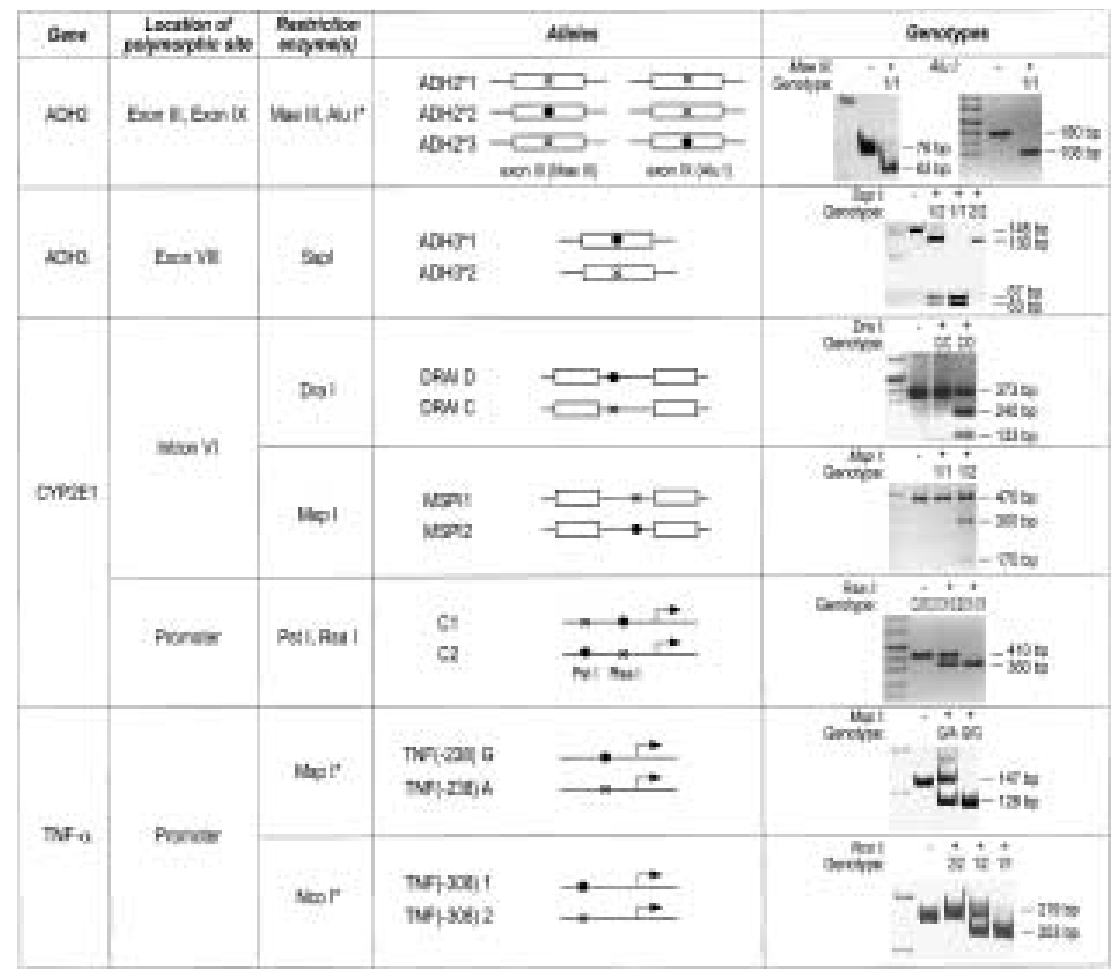

Fig. 1. Schematic representation of genes and polymorphisms analyzed in this study. The restriction enzymes used in this study are indicated. If the analyzed polymorphic site introduced or abolished the presence of a naturally occurring restriction site, this was used for the analyses. Otherwise, the enzyme recognition site was introduced by using appropriate mismatched primers for PCR amplification (enzymes indicated by a star). In the Alleles column, empty boxes indicate exons; filled circles and crosses refer to the presence or absence of the restriction enzyme sites respectively; arrows pointing rightward indicated transcription start sites. Exons, introns and the location of restriction enzyme sites are not drawn to scale. In the Genotypes column, the restriction patterns obtained for the different alleles are shown as pictures of ethidium bromide stained gels. DNA fragments were obtained by PCR amplification and digestion with the appropriate enzymes, as indicated. In each gel, the lanes without indications contain molecular weight markers. Three of the investigated polymorphisms map in exonic regions (exons III and IX of ADH2 and exon VIII of ADH3) and have been demonstrated to produce alleles which encode for proteins with increased enzymatic activity (ADH2*2, ADH3*1 (35)). Four polymorphisms are located in the CYP2El gene. Two of them (Dra I and Msp I) are in intron VI of the gene, and their functional significance-if any-is still poorly understood $(14,38,39)$; the other two (Rsa I and Pst I) are located in the promoter region of the gene and determine different levels of gene expression (28). The last two polymorphisms are in strong linkage disequilibrium, thus determining the existence of only two possible haplotypes (28). Finally, two other polymorphisms in the TNF- $\alpha$ gene lay in the promoter region of the gene, and co-localize with cis-acting sites controlling the transcriptional levels of the gene $(40,41)$.

Table 1. Prevalence of ADH2, ADH3, Cyp2E1 and TNF $\alpha$ alleles in the populations of heavy drinkers from the towns of Cormons and Campogalliano. HD: heavy drinker individuals

\begin{tabular}{|c|c|c|c|c|c|c|c|c|c|c|c|c|c|c|}
\hline & \multirow{3}{*}{$\begin{array}{c}\mathbf{N} \text {. of } \\
\text { Alleles }\end{array}$} & \multicolumn{13}{|c|}{ Alleles } \\
\hline & & \multicolumn{3}{|c|}{ ADH2-Exons III, IX } & \multicolumn{2}{|c|}{ ADH3-Exon VIII } & \multicolumn{2}{|c|}{ CYP2E1-Intron VI } & \multicolumn{2}{|c|}{ CYP2E1-Promoter } & \multicolumn{2}{|c|}{ TNF(-238) } & \multicolumn{2}{|c|}{ TNF(-308) } \\
\hline & & $A D H 2 * 1$ & $A D H 2 * 2$ & $A D H 2 * 3$ & $A D H 3 * 1$ & $A D H 3 * 2$ & MSPII & MAPI2 & $C 1$ & $C 2$ & $G$ & $A$ & 1 & 2 \\
\hline CORMONS & 158 & & & & & & & & & & & & & \\
\hline Healthy HD & 88 & $88(1)$ & $0(0)$ & $0(0)$ & $54(0.61)$ & $34(0.39)$ & $87(0.99)$ & $1(0.01)$ & $87(0.99)$ & $1(0.01)$ & $83(0.94)$ & $5(0.06)$ & $69(0.78)$ & $19(0.22)^{d}$ \\
\hline HD with ALD & 70 & $70(1)$ & $0(0)$ & $0(0)$ & $33(0.47)$ & $37(0.53)$ & $69(0.99)$ & $1(0.01)$ & $70(1)$ & $0(0)$ & $67(0.96)$ & $3(0.04)$ & $63(0.90)$ & $7(0.10)$ \\
\hline HD with cirrhosis & 18 & $18(1)$ & $0(0)$ & $0(0)$ & $9(0.50)$ & $9(0.50)$ & $18(1)$ & $0(0)$ & $18(1)$ & $0(0)$ & $18(1)$ & $0(0)$ & $15(0.83)$ & $3(0.17)$ \\
\hline CAMPOGALLIANO & 158 & & & & & & & & & & & & & \\
\hline Healthy HD & 96 & $94(0.98)$ & $2(0.02)$ & $0(0)$ & $61(0.64)$ & $35(0.36)$ & $95(0.99)$ & $1(0.01)$ & $90(0.94)$ & $6(0.06)$ & $93(0.97)$ & $3(0.03)$ & $85(0.88)$ & $11(0.12)$ \\
\hline HD with ALD & 62 & $62(1)$ & $0(0)$ & $0(0)$ & $43(0.69)$ & $19(0.31)$ & $61(0.98)$ & $1(0.02)$ & $50(0.81)$ & $12(0.19)^{\mathrm{a}}$ & $57(0.92)$ & $5(0.08)$ & $56(0.90)$ & $6(0.10)$ \\
\hline HD with cirrhosis & 12 & $12(1)$ & $0(0)$ & $0(0)$ & $7(0.58)$ & $5(0.42)$ & $11(0.92)$ & $1(0.08)$ & $8(0.67)$ & $4(0.33)^{\mathrm{b}}$ & $12(1)$ & $0(0)$ & $10(0.83)$ & $2(0.17)$ \\
\hline TOTAL & 316 & & & & & & & & & & & & & \\
\hline Healthy HD & 184 & $182(0.99)$ & $2(0.01)$ & $0(0)$ & $115(0.62)$ & $69(0.38)$ & $182(0.99)$ & $2(0.01)$ & $177(0.96)$ & $7(0.04)$ & $176(0.96)$ & $8(0.04)$ & $154(0.84)$ & $30(0.14)$ \\
\hline HD With ALD & 132 & $132(1)$ & $0(0)$ & $0(0)$ & $76(0.58)$ & $56(0.42)$ & $130(0.98)$ & $2(0.02)$ & $120(0.91)$ & $12(0.09)^{\mathrm{C}}$ & $124(0.94)$ & $8(0.06)$ & $119(0.90)$ & $13(0.10)$ \\
\hline HD with cirrhosis & 30 & $30(1)$ & $0(0)$ & $0(0)$ & $16(0.53)$ & $14(0.47)$ & $29(0.97)$ & $1(0.03)$ & $26(0.87)$ & $4(0.13)$ & $30(1)$ & $0(0)$ & $25(0.83)$ & $5(0.17)$ \\
\hline
\end{tabular}

a $\mathrm{p}=0.12$ for healthy heavy drinkers vs. heavy drinkers with ALD

$\mathrm{b}_{\mathrm{p}}=0.033$ for heavy drinkers with cirrhosis vs. heavy drinkers without cirrhosis

${ }^{c} p=0.053$ for healthy heavy drinkers vs. heavy drinkers with ALD

$\mathrm{d} p=0.046$ for healthy heavy drinkers vs. heavy drinkers with ALD 
Table 2. Correlation of the Rsa I C1/C2 genotype with the Dra I D/C genotype of cytochrome $P 4502 E 1$ in the population of heavy drinkers from Campogalliano. Allele $\mathrm{Cl}$ is defined by the presence of the Rsa I site; allele $D$ by the presence of the Dra I site

\begin{tabular}{c|ccc|c}
\hline Genotype $^{\mathbf{a}}$ & C1/C1 & C1/C2 & C2/C2 & Total \\
\hline DD & 44 & 6 & 0 & 50 \\
CD & 18 & 9 & 0 & 27 \\
CC & 0 & 1 & 1 & 2 \\
\hline Total & 62 & 16 & 1 & \\
\hline
\end{tabular}

${ }^{\mathrm{a}} \mathrm{p}<0.001$ for combined genotypic distribution

Contrary to the prevalence of allele $\mathrm{C} 2$ in the heavy drinkers from Campogalliano (0.11 allelic frequency), this allele was almost 20 times less frequent in the heavy drinkers from Cormons (only 1 out of 158 total analyzed chromosomes; 0.006). Because the genetic background of the two towns is remarkably different (see Discussion), this is not surprising. In individuals from Cormons, allele $\mathrm{ADH} 3 * 2$ of the Ssp I polymorphism in exon VIII of the ADH3 gene was unequally distributed between heavy drinkers with or without ALD $(39 \%$ and $53 \%$ respectively, see Table 1), suggesting a contribution of this allele to disease development. This contribution reached striking statistical significance when the frequency of homozygosity for this allele was analyzed. Eleven out of 35 patients $(31 \%)$ with chronic liver disease or cirrhosis were homozygous for the ADH3*2 allele, but homozygosity was found only in 3 out of $44(7 \%)$ healthy heavy drinkers $(p=0.004$ for patients with ALD vs heavy drinkers controls, Table 3).

The contribution of homozygosity for allele ADH $3 * 2$ to the development of alcoholic liver damage can be better observed if the population of individuals homozygous for the $\mathrm{Cl}$ allele of P4502El (the nonpredisposing allele) is considered in the whole dataset. Homozygosity for ADH3*2 is present only in 7 out of $85(8 \%)$ normal heavy drinkers from the total population of $\mathrm{Cl} / \mathrm{Cl}$ individuals from the two towns, yet it increases to 13 out of $55(24 \%)$ in patients with $\operatorname{ALD}(p=0.012)$, and to 4 out of $11(36 \%)$ when only cirrhotic patients are considered $(p=0.055$; Figure 2$)$. Heavy drinkers homozygous for $\mathrm{ADH} 3 * 2$ have a relative risk of 3.5 times higher (C.I. 1.28-9.30) of developing ALD and a risk of 4.0 times higher (C.I. 1.1-15.8) of developing alcoholic cirrhosis.

\section{Combined Genotype Protecting Against Alcoholic \\ Liver Disease}

The results reported herein indicate that, depending on allelic frequencies of the two analyzed populations, the presence of either at least one allele $\mathrm{C} 2$ of cytochrome P4502El (as in Campogalliano) or of the homozygosity for the ADH $3 * 2$ allele (as in Cormons) is a predisposing factor for the development of alcoholic liver disease. Accordingly, if in the overall population of heavy drinkers subjects from the two towns, those with a combined genotype having $\mathrm{Cl} / \mathrm{Cl}$ homozygosity at the CYP2E1 locus and not being homozygous for $\mathrm{ADH}^{*} 2$ are analyzed, a remarkably different distribution is found according to disease development (Figure 3). Seventy-eight of 92 $(85 \%)$ of these individuals are in the healthy heavy

Table 3. Prevalence of ADH3, Cyp2E1 and TNF $\alpha$ genotypes in the populations of heavy drinkers from the towns of Cormons and Campogalliano

\begin{tabular}{|c|c|c|c|c|c|c|c|c|c|c|c|c|c|}
\hline & \multirow{3}{*}{$\begin{array}{l}\text { N. of } \\
\text { Cases }\end{array}$} & \multicolumn{12}{|c|}{ Genotypes } \\
\hline & & \multicolumn{3}{|c|}{ ADH3-Exon VIII } & \multicolumn{3}{|c|}{ CYP2E1-Promoter } & \multicolumn{3}{|c|}{ TNF $\alpha$-Promoter $(-238)$} & \multicolumn{3}{|c|}{ TNF $\alpha$-Promoter $(-308)$} \\
\hline & & $A D H 3 * 1 / 1$ & $A D H 3 * 1 / 2$ & $A D H 3 * 2 / 2$ & $C 1 / C 1$ & $C 1 / C 2$ & $C 2 / C 2$ & $G / G$ & $A / G$ & $A / A$ & $1 / 1$ & $1 / 2$ & $2 / 2$ \\
\hline CORMONS & 79 & & & & & & & & & & & & \\
\hline Healthy individuals & 44 & $13(29 \%)$ & $28(64 \%)$ & $3(7 \%)$ & $43(98 \%)$ & $1(2 \%)$ & $0(0 \%)$ & $39(89 \%)$ & $5(11 \%)$ & $0(0 \%)$ & $29(66 \%)$ & $11(25 \%)$ & $4(9 \%)$ \\
\hline Patients with ALD & 35 & $9(26 \%)$ & $15(43 \%)$ & $11(31 \%)^{a}$ & $35(100 \%)$ & $0(0 \%)$ & $0(0 \%)$ & $32(91 \%)$ & $3(9 \%)$ & $0(0 \%)$ & $29(83 \%)$ & $5(14 \%)$ & $1(3 \%)$ \\
\hline Patients with cirrhosis & 9 & $3(33 \%)$ & $3(33 \%)$ & $3(33 \%)$ & $9(100 \%)$ & $0(0 \%)$ & $0(0 \%)$ & $9(100 \%)$ & $0(0 \%)$ & $0(0 \%)$ & $7(78 \%)$ & $1(11 \%)$ & $1(11 \%)$ \\
\hline CAMPOGALLIANO & 79 & & & & & & & & & & & & \\
\hline Healthy individuals & 48 & $18(38 \%)$ & $25(52 \%)$ & $5(10 \%)$ & $42(88 \%)$ & $6(12 \%)$ & $0(0 \%)$ & $45(94 \%)$ & $3(6 \%)$ & $0(0 \%)$ & $39(81 \%)$ & $7(15 \%)$ & $2(4 \%)$ \\
\hline Patients with ALD & 31 & $16(52 \%)$ & $11(35 \%)$ & $4(13 \%)$ & $20(64 \%)$ & $10(32 \%)^{d}$ & $1(4 \%)$ & $26(84 \%)$ & $5(16 \%)$ & $0(0 \%)$ & $26(84 \%)$ & $4(13 \%)$ & $1(3 \%)$ \\
\hline Patients with cirrhosis & 6 & $3(50 \%)$ & $1(17 \%)$ & $2(33 \%)$ & $2(33 \%)$ & $4(67 \%)^{\mathrm{e}}$ & $0(0 \%)$ & $6(100 \%)$ & $0(0 \%)$ & $0(0 \%)$ & $4(67 \%)$ & $2(33 \%)$ & $0(0 \%)$ \\
\hline TOTAL & 158 & & & & & & & & & & & & \\
\hline Healthy individuals & 92 & $31(34 \%)$ & $53(58 \%)$ & $8(9 \%)$ & $85(92 \%)$ & $7(8 \%)$ & $0(0 \%)$ & $84(91 \%)$ & $8(9 \%)$ & $0(\%)$ & $68(74 \%)$ & $18(20 \%)$ & $6(7 \%)$ \\
\hline Patients with ALD & 66 & $25(38 \%)$ & $26(39 \%)$ & $15(23 \%) b$ & $55(83 \%)$ & $10(15 \%)$ & $1(2 \%)$ & $58(88 \%)$ & $8(12 \%)$ & $0(0 \%)$ & $55(83 \%)$ & $9(14 \%)$ & $2(3 \%)$ \\
\hline Patients with cirrhosis & 15 & $6(40 \%)$ & $4(27 \%)$ & $5(33 \%)^{\mathrm{C}}$ & $11(73 \%)$ & $4(27 \%)^{f}$ & $0(0 \%)$ & $15(100 \%)$ & $0(0 \%)$ & $0(0 \%)$ & $11(73 \%)$ & $3(20 \%)$ & $1(7 \%)$ \\
\hline $\begin{array}{l}{ }^{a} p=0.004 \text { for healthy } h \\
b_{p}=0.14 \text { for healthy he } \\
{ }^{c} p=0.052 \text { for heavy dri } \\
{ }^{d} p=0.016 \text { for healthy } h \\
e_{p}=0.010 \text { for heavy dri } \\
{ }^{f} p=0.082 \text { for heavy dri }\end{array}$ & $\begin{array}{l}\text { y drinke } \\
\text { drinker } \\
\text { ers with } \\
\text { y drink } \\
\text { ers with } \\
\text { ers with }\end{array}$ & $\begin{array}{l}\text { vs. heavy drin } \\
\text { s. heavy drink } \\
\text { rhosis vs. heav } \\
\text { vs. heavy drin } \\
\text { rhosis vs. heav } \\
\text { rhosis vs. heav }\end{array}$ & $\begin{array}{l}\text { kers with ALD } \\
\text { ers with ALD } \\
\text { y drinkers wit } \\
\text { kers with ALI } \\
\text { y drinkers wi } \\
\text { y drinkers wit }\end{array}$ & $\begin{array}{l}\text { thout cirrhosi } \\
\text { thout cirrhosi } \\
\text { hout cirrhosi }\end{array}$ & & & & & & & & & \\
\hline
\end{tabular}




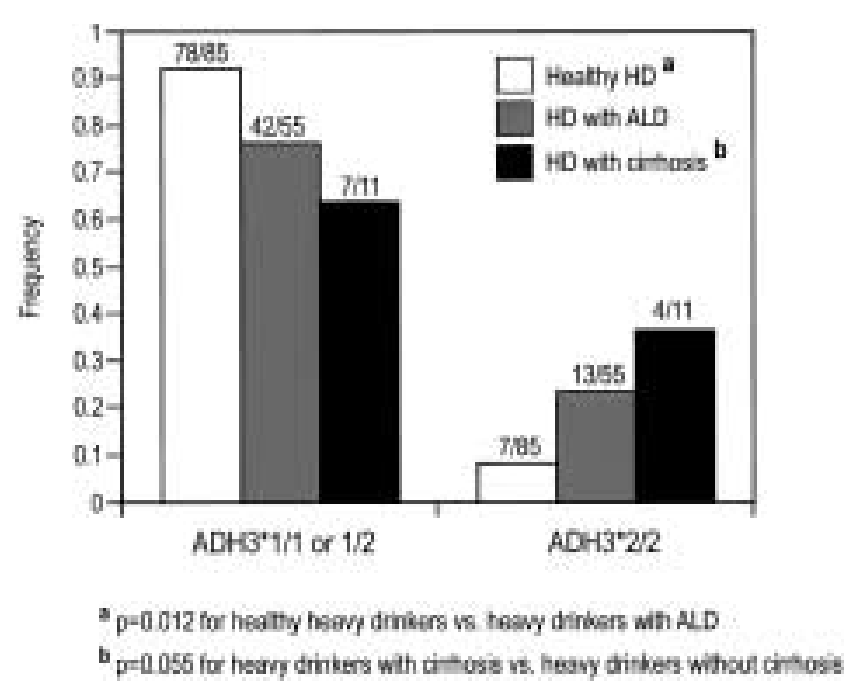

Fig. 2. Homozygosity for allele ADH3*2 of the alcohol dehydrogenase-3 gene is associated with ALD. The frequencies of the ADH $3 * 2 / \mathrm{ADH} 3 * 2$ genotype (bars on the right side) and of the other two reciprocal genotypes (bars on the left side) are shown in healthy controls, ALD and cirrhotic patients all being homozygous for allele $\mathrm{Cl}$ of the cytochrome P450El gene. The numbers on top of each bar indicate the number of individuals with the indicated genotype out of the total individuals in that category. HD: heavy drinker individuals. ALD: ethanol-induced liver damage.

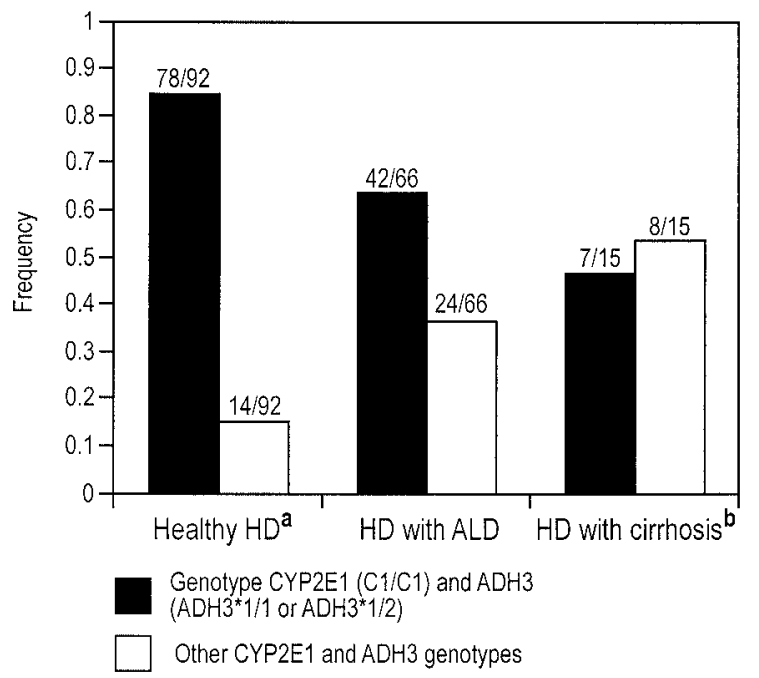

${ }^{a} p=0.002$ for healthy heavy drinkers vs. heavy drinkers with ALD

${ }^{b} p=0.009$ for heavy drinkers with cirrhosis vs. heavy drinkers without cirrhosis

Fig. 3. Combined ADH3 and CYP2E1 genotypes at lower risk of developing ALD. The graph shows the frequency of the combined genotype defined by homozygosity for allele $\mathrm{Cl}$ of the cytochrome P45021 gene and homozygosity or heterozygosity for allele ADH3*1 of the alcohol dehydrogenase-3 gene in healthy individuals, ALD and cirrhotic patients. The numbers on top of each bar indicate the number of individuals with the indicated genotype (filled bars) or with all other possible genotypes at the two genes (empty bars) out of the total individuals in that category. drinker group, 42 of $66(64 \%)$ in the ALD group $(p=0.002)$, and only 7 of $15(47 \%)$ in the cirrhosis group $(p=0.009)$. This indicates that this combined genotype is protective against the development of alcoholic liver disease. On the contrary, individuals either having allele C2 of CYP2E1 or homozygous for $\mathrm{ADH} 3 * 2$ have a risk 3.2 times higher (C.I. 1.5-6.7) of developing ALD and 4.3 times higher (C.I. 1.4-12.5) of developing alcoholic cirrhosis.

\section{Discussion}

Alcoholic liver disease is a multifactorial disease resulting from the interaction of environmental, behavioral, and dietary factors (among which alcohol consumption is the most relevant one) with genetic factors. Clearly, multiple genes are involved in the predisposition to develop liver disease, and most likely, these genes differ in various ethnic groups. Genetic dissection of this complex trait is further hampered because the genes involved can influence not only the probability of disease development but also the drinking behavior, thus changing the frequencies of allelic distribution between alcoholic and nonalcoholic individuals $(8,10,17,21,34)$. To avoid this interference, we focused our attention on two cohorts of genetically homogenous, unselected heavy drinkers in the general population. The two towns in which this study was performed, Cormons and Campogalliano, are located in different regions of the northern part of Italy. The former is in the FriuliVenezia Giulia Region, approximately $50 \mathrm{~km}$ away from Trieste, in an area well recognized for wine production. This geographical area is in the most eastern part of Italy and the ethnical background of its population has been strongly influenced by the immigration of South Slavic populations. In contrast, Campogalliano is placed in the Po river valley, not far from Modena, and its population is an old genetic admixture of indigenous inhabitants with Longobard invaders in the 5th century. Although we cannot formally exclude the possibility that heavy drinkers with or without ALD have subtly different population genetic histories, we are keen to believe that this possibility is remote, owing to lack of cultural, religious, behavioral or census stratification.

The results obtained by the genetic analysis of the vast majority $(\sim 85 \%)$ of the heavy drinkers in these two populations indicate that allele $\mathrm{C} 2$ of cytochrome P4502E1 and allele ADH3*2 of alcohol dehydrogenase- 2 are major independent genetic determinants of susceptibility to ALD, with a relative contribution to disease development which is according to their relative frequencies in the population.

Studies conducted in Japanese (12) and Caucasian (16) individuals have already indicated that the frequency of the C2 allele of CYP2EI-characterized by increased levels of gene expression (28)-is significantly higher in heavy drinkers patients with severe ALD. However, other investi- 
gations did not confirm this finding $(13,14)$. This apparent discrepancy is likely to be due to the variable prevalence of this allele in the different populations analyzed. Also in our work, association of the C2 allele with the development of ALD was observed only in Campogalliano, where the overall frequency of the allele in alcoholics was 0.11 , while in Cormons, where the allelic frequency was $<0.01-$ similar to the studies which failed to detect a positive association $(13,14)$ - other genotypes primarily determined the risk of ALD. One of these genotypes is the homozygosity for allele $\mathrm{ADH} 3 * 2$ of ADH3. In individuals not possessing allele $\mathrm{C} 2$ of CYP2E1, the percentage of $\mathrm{ADH} 3 * 2$ homozygotes raised from $8 \%$ in healthy heavy drinkers, to $24 \%$ in ALD patients, and to $36 \%$ in ALD patients with cirrhosis. The ADH3*2 allele encodes for the $\gamma 2$ enzymatic subunit of ADH3, which has lower ethanol oxidation activity. It can be speculated that, in the presence of this isoform, ethanol is primarily metabolized through the microsomal cytochrome P4502El-mediated pathway, with a consequent higher production of toxic free radicals as end products. In a previous study in the British population, Day and collaborators reported an association between allele $\mathrm{ADH}^{*} 1$ (the rapid alcohol-metabolizing allele) and ALD (18). This study, however, which was performed by comparing patients with alcoholic liver disease to normal individuals, showed only minor differences in allele distribution between the two groups and was not confirmed by another independent investigation (11).

As far as the other polymorphisms investigated in this study are concerned, the results obtained confirm that the frequencies of the $\mathrm{ADH}_{2} * 2$ and $\mathrm{ADH} 2 * 3$ alleles of ADH2 and of the MSPI2 allele of CYP2E1 are very low in Caucasians $(14,35)$ and their distribution does not vary among the different groups considered. With respect to the two polymorphisms in the TNF- $\alpha$ gene, our results do not suggest any association between these polymorphisms and the susceptibility to ALD in our population. We have also analyzed the possibility that either TNF- $\alpha$ polymorphisms could contribute to ALD development in combination with either ADH $3 * 2$ or C2, or both, but failed to find any of these associations. Obviously, this conclusion needs to be further challenged in a larger sample population.

This study, which to our knowledge is the first one conducted by comparing healthy heavy drinkers to heavy drinkers with ALD in the general population, identifies two genetic polymorphisms predisposing persons to alcoholic liver damage. These polymorphisms are different in the two different populations analyzed, even if both of them are of Caucasian derivation and live in two towns in the same country merely a few hundred kilometers apart. From the genetic standpoint, these findings further indicate that this type of allelic association studies require that the analyzed sample population is genetically homogeneous to possibly permit the study of the inheritance of few ancestral chromosomal segments.

The results obtained by this study also reinforce the notion that alcoholic liver disease is multigenic and that different genes can be primarily responsible for its development in different ethnic groups. Clearly, the genes analyzed in this study are not the only ones involved in the process. Further candidates have to be sought among the genes involved in liver metabolism, mediating the response to toxic effects of ethanol metabolism end products, responsible for the production of inflammatory cytokines, triggering the development of fibrosis, among several others. Proving this concept and finding the relevant genes will require very large numbers of cases with or without alcoholic liver disease. The use of methods recently adopted for studying polygenic diseases and involving family studies will better help approaching this issue $(36,37)$.

\section{Acknowledgments}

This work was supported by Grant \# E396 from Telethon Italy. F.M. is supported by a fellowship from Fondo Studio Fegato, Trieste-Modena. The authors wish to thank Dr. Lory S. Croce' and Dr. Franco Sasso, University of Trieste Medical School, for their critical reading of the manuscript and helpful suggestions.

\section{References}

1. Klatsky AL, Armstrong MA, Friedman GD. (1992) Alcohol and mortality. Ann. Int. Med. 117: 646-654.

2. Lieber CS. (1994) Alcohol and the liver: 1994 update. Gastroenterol. 106:1085-1105.

3. Bouchier IAD, Hislop WS, Prescott RJ. (1992) A prospective study of alcoholic liver disease and mortality. J. Hepatol. 16: 290-297.

4. Becker U, Deis A, Sorensen TIA, Gronbaek M, Borch-Johnsen K, al. e. (1996) Prediction of liver disease by alcohol intake, sex, and age: a prospective population study. Hepatol. 23: 1025-1029.

5. Derr RF, Porta EA, Larkin EC, Rao GA. (1990) Is ethanol per se hepatotoxic? J. Hepatol. 10: 381-386.

6. Bellentani S, Saccoccio G, Costa G, et al. (1997) Drinking habits as cofactors of risk for alcohol induced liver damage. The Dionysos Study Group. Gut 41: 845-850.

7. Hrubec Z, Omenn GS. (1981) Evidence of genetic predisposition to alcoholic cirrhosis and psychosis: twin concordances for alcoholism and its biological end points by zygosity among male veterans. Alcohol Clin. Exp. Res. 5: 207-2 15.

8. Chao YC, Liou SR, Chung YY, et al. (1994) Polymorphism of alcohol and aldehyde dehydrogenase genes and alcoholic cirrhosis in Chinese patients. Hepatol. 19: 360-366.

9. Chao YC, Young TH, Chang WK, Tang HS, Hsu CT. (1995) An investigation of whether polymorphisms of cytochrome P4502El are genetic markers of susceptibility to alcoholic end-stage organ damage in a Chinese population. Hepatol. 22: 1409-1414.

10. Chao YC, Young TH, Tang HS, Hsu CT. (1997) Alcoholism and alcoholic organ damage and genetic polymorphisms of alcohol metabolizing enzymes in Chinese patients. Hepatol. 25: 112-117.

11. Poupon RE, Nalpas B, Coutelle C, Fleury B, Couzigou P, Higueret D. (1992) Polymorphism of alcohol dehydrogenase, alcohol and aldehyde dehydrogenase activities: implication 
in alcoholic cirrhosis in white patients. The French Group for Research on Alcohol and Liver. Hepatol. 15: 1017-1022.

12. Tsutsumi M, Takada A, Wang JS. (1994) Genetic polymorphisms of cytochrome P4502El related to the development of alcoholic liver disease. Gastroenterol. 107: 1430-1435.

13. Carr LG, Hartleroad JY, Liang Y, Mendenhall C, Moritz T, Thomasson H. (1995) Polymorphism at the P450IIEl locus is not associated with alcoholic liver disease in Caucasian men. Alcohol Clin. Exp. Res. 19: 182-184.

14. Savolainen VT, Pajarinen J, Perola M, Penttila A, Karhunen PJ. (1997) Polymorphism in the cytochrome P450 2El gene and the risk of alcoholic liver disease. J. Hepatol. 26: 55-61.

15. Maezawa Y, Yamauchi M, Toda G. (1994) Association between restriction fragment length polymorphism of the human cytochrome P450IIEl gene and susceptibility to alcoholic liver cirrhosis. Am. J. Gastroenterol. 89: 561-565.

16. Pirmohamed M, Kitteringham NR, Quest LJ, et al. (1995) Genetic polymorphism of cytochrome P4502El and risk of alcoholic liver disease in Caucasians. Pharmacogenetics 5: 351-357.

17. Yamauchi M, Maezawa Y, Toda G, Suzuki H, Sakurai S. (1995) Association of a restriction fragment length polymorphism in the alcohol dehydrogenase 2 gene with Japanese alcoholic liver cirrhosis. J. Hepatol. 23: 519-523.

18. Day CP, Bashir R, James OF, et al. (1991) Investigation of the role of polymorphisms at the alcohol and aldehyde dehydrogenase loci in genetic predisposition to alcohol-related endorgan damage. Hepatol. 14: 798-801.

19. Day CP, James OF, Bassendine MF, Crabb DW, Li TK. (1993) Alcohol dehydrogenase polymorphisms and predisposition to alcoholic cirrhosis. Hepatol. 18: 230-232.

20. McClain C, Hill D, Schmidt J, Diehl AM. (1993) Cytokines and alcoholic liver disease. Semin. Liver Dis. 13: 170-182.

21. Enomoto N, Takase S, Takada N, Takada A. (1991) Alcoholic liver disease in heterozygotes of mutant and normal aldehyde dehydrogenase-2 genes. Hepatol. 13: 1071-1075.

22. Grove J, Daly AK, Bassendine MF, Day CP. (1997) Association of a tumor necrosis factor promoter polymorphism with susceptibility to alcoholic steatohepatitis. Hepatol. 26: 143146.

23. Wilhelmsen KC. (1997) Does tumor necrosis factor play a role in alcoholic steatohepatitis? The potential pitfalls of a casecontrolled allelic association analysis. Hepatol. 26: 232- 233.

24. Bellentani S, Tiribelli C, Saccoccio G, et al. (1994) Prevalence of chronic liver disease in the general population of northern Italy: the Dionysos Study. Hepatol. 20: 1442-1449.

25. Block G, Hartmann AM, Dresser CM. (1986) A data-based approach to diet questionnaire design and testing. Am. J. Epidemiol. 124: 453-469.

26. Cubean J, Pequinot G. (1980) La technique du questionnaire alimentaire quantitatif utilisé par la section nutrition de l'INSERM. Rev. Epidemiol. Santé Publique 28: 367-372.

27. Sambrook J, Fritsch EF, Maniatis T. (1989) Molecular Cloning. A Laboratory Manual/II Edition. Cold Spring Harbor, NY: Cold Spring Harbor Laboratory.

28. Hayashi S, Watanabe J, Kawajiri K. (1991) Genetic polymorphisms in the $5^{\prime}$-flanking region change transcriptional regulation of the human cytochrome P450IIEl gene. J. Biochem. 110: $559-565$.

29. Groppi A, Begueret J, Iron A. (1990) Improved methods for genotype determination of human alcohol dehydrogenase $(\mathrm{ADH})$ at $\mathrm{ADH} 2$ and $\mathrm{ADH} 3$ loci by using polymerase chain reaction-directed mutagenesis. Clin. Chem. 36: 1765-1768.

30. Sokal RR, Rohlf FJ. (1981) Biometry. New York: Freeman.

31. Zar JH. (1984) Biostatistical Analysis. Englewood Cliffs, NJ: Prentice-Hall.

32. Weir BS. (1996) Genetic Data Analysis II. Sunderland, MA: Sinauer Associates.

33. Fleiss JL. (1981) Statistical methods for rates and proportion. New York: Wiley $\delta$ Sons.

34. Thomasson HR, Edenberg HJ, Crabb DW, et al. (1991) Alcohol and aldehyde dehydrogenase genotypes and alcoholism in Chinese men. Am. J. Hum. Genet. 48: 677-681.

35. Bosron WF, Ehrig T, Li TK. (1993) Genetic factors in alcohol metabolism and alcoholism. Semin. Liver Dis. 13: 126-135.

36. Lander ES, Schork NJ. (1994) Genetic dissection of complex traits. Science 265: 2037-2048.

37. Spielman RS, Ewens WJ. (1996) The TDT and other familycased tests for linkage disequilibrium and association. Am. J. Hum. Genet. 59: 983-989.

38. Uematsu F, Kikuchi H, Abe T, et al. (1991) MspI polymorphism of the human CYP2El gene. Nucleic Acids Res. 19: 5797.

39. Hirvonen A, Husgafvel-Pursiainen K, Anttila S, Karjalainen A, Vainio H. (1993) The human CYP2El gene and lung cancer: Dra I and Rsa I restriction fragment length polymorphisms in a Finnish study population. Carcinogenesis 14: 85-88.

40. Wilson AG, Symons JA, McDowell TL, McDevitt HO, Duff GW. (1997) Effects of a polymorphism in the human tumor necrosis factor alpha promoter on transcriptional activation. Proc. Natl. Acad. Sci. USA 94: 3195-3199.

41. Drouet C, Shakhov AN, Jongeneel CV. (1991) Enhancers and transcription factors controlling the inducibility of the tumor necrosis factor-alpha promoter in primary macrophages. $\mathrm{J}$. Immunol. 147: 1694-1700. 